\title{
Recovery of vanadium from alkaline leaching solution from roasted stone coal
}

\author{
Sisi Long ${ }^{\mathrm{a}}$, Qiming Feng ${ }^{\mathrm{a}}$, Guofan Zhang ${ }^{\mathrm{a}, *}$, Dongsheng $\mathrm{He}^{\mathrm{b}}$ \\ a School of Resources Processing and Bioengineering, Central South University, Changsha 410083 China \\ b School of Environment and Civil Engineering, Wuhan Institute of Technology, Wuhan 430073 China
}

*Corresponding author, e-mail: zhangguofan2002@163.com

Received 2 Dec 2012

Accepted 24 Jul 2013

\begin{abstract}
A two-stage purification-extraction-stripping- $\mathrm{NH}_{4} \mathrm{NO}_{3}$ technology to precipitate $\mathrm{V}_{2} \mathrm{O}_{5}$ was developed based on the characteristics of the alkaline leaching solution produced from roasted stone coal. Factors influencing purification, extraction, stripping, and $\mathrm{NH}_{4} \mathrm{VO}_{3}$ precipitation were studied. Vanadium can be recovered effectively from alkaline leaching solutions using this technology. The purity of the $\mathrm{V}_{2} \mathrm{O}_{5}$ product was $99.6 \%$, thereby meeting national standards. The overall vanadium recovery was $90.9 \%$.
\end{abstract}

KEYWORDS: vanadium pentoxide, purification, extraction

\section{INTRODUCTION}

The classical technology for extracting vanadium from stone coal has two main problems, low vanadium recovery $(<50 \%)$ and the production of environmental pollutants ${ }^{1,2}$, and is therefore being eliminated gradually. In recent years, researchers have developed new technologies ${ }^{3-8}$, such as oxidizing roastingacid leaching-salt production-extraction-deposition with ammonium-thermal decomposition, oxidizing roasting-acid leaching-extraction-deposition with ammonium-thermal decomposition, and oxidizing roasting-acid leaching and purification-deposition with ammonium-thermal decomposition. In contrast with the classical technology, these technologies have advantages of higher recovery, simpler flowsheet and lower cost. However, they require acid as a leaching agent and this causes problems such as high acid consumption, a requirement for acid-resistance equipment, and treatment of acidified wastewater and solid residues before discharge ${ }^{4,8}$. To overcome the disadvantages of the acid leaching technology, we investigated an alkali leaching technology 9,10 . In contrast with acid leaching technologies, the advantages of the alkali leaching technology are, reduced impurities in the leaching solution, which is better for subsequent processes; low requirements for corrosion resistance of equipment; direct discharge of wastewater and solid residues after simple treatment. Using our previous results from the development of an alkali leaching technology ${ }^{9}$, we present here a detailed report on the recovery of vanadium from alkali leaching solutions.

\section{MATERIALS AND METHODS}

Materials

The stone coal in this study is black and rock-like in appearance. This fuel with low calorific value can be treated as a polymetallic ore. It contains mostly quartz, illite, kaolinite, pyrite, and $18 \%$ organic matter with main chemical composition being $1 \% \mathrm{~V}_{2} \mathrm{O}_{5}$, $68 \% \mathrm{SiO}_{2}, 6 \% \mathrm{Al}_{2} \mathrm{O}_{3}$, and $5 \% \mathrm{Fe}_{2} \mathrm{O}_{3}$. The vanadium distribution in the silicates is approximately $80 \%$. The loss on burning of the organic matter in the stone coal is approximately $17 \%$.

The raw stone coal was roasted at $850{ }^{\circ} \mathrm{C}$ for $3 \mathrm{~h}$ and then leached with $\mathrm{NaOH}$ solution at a certain temperature to obtain an alkaline leaching solution containing vanadium. Table 1 gives the chemical composition of the alkaline leaching solution where the main elements in solution are $\mathrm{V}, \mathrm{Si}$, and $\mathrm{Na}$, with traces of $\mathrm{Al}$ and As. The Si concentration reaches $63.23 \mathrm{~g} / \mathrm{l} . \mathrm{Si}, \mathrm{Al}$ and As are impurities which should be removed to ensure the final product purity.

\section{Methods}

The $\mathrm{Si}, \mathrm{Al}$, and As impurities in solution were removed through chemical precipitation in two steps (two-stage purification). After the two-stage purification, almost all impurities were removed, and a purified liquor was obtained. The impurities ( $\mathrm{Si}$ and $\mathrm{Al}$ ) in solution were removed by chemical precipitation by addition of $\mathrm{H}_{2} \mathrm{SO}_{4}, \mathrm{Mg}\left(\mathrm{NO}_{3}\right)_{2}$, and ammonia. After extracting vanadium from the purified liquor using an extractant (10 vol \% N235, $20 \mathrm{vol} \%$ secondary 
Table 1 Chemical composition of alkaline leaching solution.

\begin{tabular}{lccccc}
\hline Constituent & $\mathrm{V}_{2} \mathrm{O}_{5}$ & $\mathrm{SiO}_{2}$ & $\mathrm{Al}_{2} \mathrm{O}_{3}$ & $\mathrm{As}$ & $\mathrm{Na}_{2} \mathrm{O}$ \\
\hline Concentration $(\mathrm{g} / \mathrm{l})$ & 10.40 & 63.23 & 0.56 & 0.023 & 54.75 \\
\hline
\end{tabular}

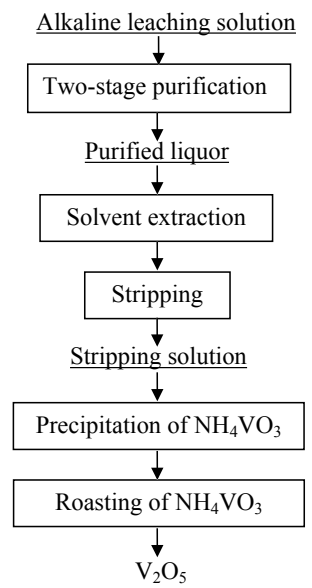

Fig. 1 Principle flowsheet for extracting vanadium from alkaline leaching.

octyl alcohol and 70 vol \% sulphonated kerosene), $\mathrm{NaOH}$ was used as vanadium stripping agent. N235 is a tertiary amine with structure $\mathrm{N}\left[\mathrm{C}_{n} \mathrm{H}_{2 n+1}\right]_{3}(n=$ 8-10). Ammonium metavanadate was crystallized from the stripping solution by $\mathrm{NH}_{4} \mathrm{NO}_{3}$ addition, and high quality $\mathrm{V}_{2} \mathrm{O}_{5}$ was obtained by calcination of ammonium metavanadate at high temperature. The principle flowsheet for extracting vanadium from alkaline leaching solution is shown in Fig. 1.

\section{RESULTS AND DISCUSSION}

\section{Purification}

The principle flowsheet for purification of the leaching solution in Fig. 2 consists of two steps. First, most

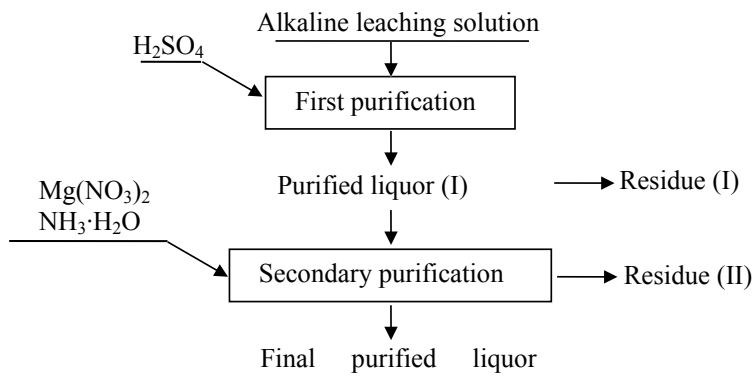

Fig. 2 Principle flowsheet of the purification of alkaline leaching.

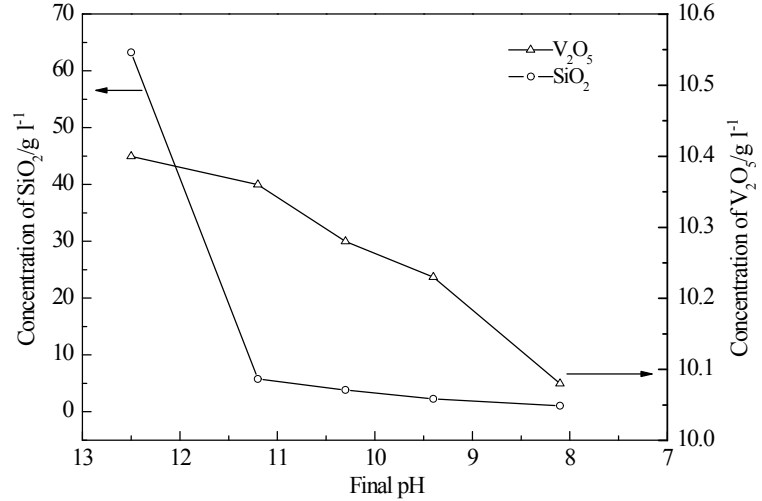

Fig. 3 Effect of final $\mathrm{pH}$ on purification efficiency.

$\mathrm{Si}$ and $\mathrm{Al}$ are removed by adjusting the solution $\mathrm{pH}$ to a suitable value with $\mathrm{H}_{2} \mathrm{SO}_{4}$. As and the remaining $\mathrm{Si}$ are removed by $\mathrm{Mg}\left(\mathrm{NO}_{3}\right)_{2}$ and ammonia addition and the chemical precipitation of low solubility $\mathrm{MgSiO}_{3}$ and $\mathrm{MgNH}_{4} \mathrm{AsO}_{4}$. The corresponding reactions are ${ }^{11,12}$ :

$$
\begin{gathered}
\mathrm{SiO}_{3}^{-}+2 \mathrm{H}^{+} \longrightarrow \mathrm{H}_{2} \mathrm{SiO}_{3} \downarrow \\
\mathrm{AlO}_{2}^{-}+\mathrm{NH}_{3} \mathrm{H}_{2} \mathrm{O} \longrightarrow \mathrm{Al}(\mathrm{OH})_{3} \downarrow+\mathrm{NH}_{4}^{+} \\
\mathrm{Mg}^{2+}+\mathrm{SiO}_{3}^{2-} \longrightarrow \mathrm{MgSiO}_{3} \downarrow \\
\mathrm{HAsO}_{4}^{2-}+\mathrm{NH}_{4}^{+}+\mathrm{Mg}^{2+} \longrightarrow \mathrm{MgNH}_{4} \mathrm{AsO}_{4} \downarrow+\mathrm{H}^{+}
\end{gathered}
$$

Factors affecting the purification efficiency are the purification temperature, purification time, reagent dosage, stirring speed, and $\mathrm{H}_{2} \mathrm{SO}_{4}$ addition rate. For the first step, the final solution $\mathrm{pH}$ is the key influencing factor ${ }^{13}$. Suitable purification conditions acquired through a series of experiments are as follows: purification temperature at ambient temperature, purification time of $1 \mathrm{~h}, \mathrm{H}_{2} \mathrm{SO}_{4}$ concentration of $50 \%(\mathrm{v} / \mathrm{v}), \mathrm{H}_{2} \mathrm{SO}_{4}$ addition rate of $2 \mathrm{ml} / \mathrm{min}$ and stripping speed of $500 \mathrm{rpm}$. Under these conditions, the relationship between the final solution $\mathrm{pH}$ and desilication efficiency was studied. Fig. 3 shows the effect of final $\mathrm{pH}$ on $\mathrm{Si}$ and $\mathrm{V}$ concentration in the purified liquor. The $\mathrm{Si}$ and $\mathrm{V}$ concentration decreased with decrease in final $\mathrm{pH}$. A certain amount of $\mathrm{V}$ was therefore lost in the desilication process. The optimal final $\mathrm{pH}$ should ensure maximum desilication efficiency and minimal V loss. From Fig. 3, it appears that the suitable final $\mathrm{pH}$ is $8-9$.

Under the above conditions, the first purification experiments were carried out with results shown in Table 2. The desilication efficiency reached $97.9 \%$ with loss of efficiency of vanadium of $3.4 \%$. After the first purification, there was a certain amount of $\mathrm{Si}$ and $\mathrm{As}$ in the purified liquor, which should be 
Table 2 Purification results.

\begin{tabular}{|c|c|c|c|c|c|c|}
\hline \multirow[t]{2}{*}{ Purification } & \multicolumn{2}{|c|}{$\begin{array}{l}\text { Grade of } \\
\text { purified } \\
\text { liquid }(\mathrm{g} / \mathrm{l})\end{array}$} & \multicolumn{2}{|c|}{$\begin{array}{l}\text { Recovery of } \\
\text { purification } \\
\text { residue }(\%)\end{array}$} & \multicolumn{2}{|c|}{$\begin{array}{l}\text { Recovery of } \\
\text { purified } \\
\text { liquid }(\%)\end{array}$} \\
\hline & $\mathrm{V}_{2} \mathrm{O}_{5}$ & $\mathrm{SiO}_{2}$ & $\mathrm{~V}_{2} \mathrm{O}_{5}$ & $\mathrm{SiO}_{2}$ & $\mathrm{~V}_{2} \mathrm{O}_{5}$ & $\mathrm{SiO}_{2}$ \\
\hline First & 10.25 & 1.35 & 3.4 & 97.9 & 96.6 & 2.1 \\
\hline Second & 10.10 & 0.066 & 2.4 & 95.2 & 97.6 & 4.8 \\
\hline
\end{tabular}

Table 3 Chemical compositions of final purified liquor.

\begin{tabular}{lccccc}
\hline Constituent & $\mathrm{V}_{2} \mathrm{O}_{5}$ & $\mathrm{SiO}_{2}$ & $\mathrm{Al}_{2} \mathrm{O}_{3}$ & $\mathrm{As}$ & $\mathrm{Na}_{2} \mathrm{O}$ \\
\hline Concentration $(\mathrm{g} / \mathrm{l})$ & 10.10 & 0.066 & 0.075 & 0.0013 & 54.35 \\
\hline
\end{tabular}

removed through the second purification step. The experimental conditions of the second purification experiments were reagent dosage of $8 \mathrm{~g} \mathrm{Mg}\left(\mathrm{NO}_{3}\right)_{2}$ and $10 \mathrm{ml}$ ammonia per litre of solution, purification temperature of $60^{\circ} \mathrm{C}$, purification time of $1 \mathrm{~h}$, stirring speed of $500 \mathrm{rpm}$. The result is shown in Table 2 with the concentration of impurities in the final purified liquor given in Table 3. After the second purification (Table 2), the desilication efficiency was $95.2 \%$, and efficiency of vanadium loss was $2.4 \%$. The desilication efficiency and efficiency of vanadium loss in the overall purification process were $99.9 \%$ and $5.8 \%$, respectively. The impurity concentrations (Si:Al and As) in the final purified liquor were low, and these concentrations will not affect the subsequent processes.

\section{Solvent extraction}

Extraction and stripping processes were necessary to enrich vanadium. The composition of the chosen extractant was 10 vol \% N235, 20 vol \% secondary octyl alcohol and 70 vol \% sulphonated kerosene. The $\mathrm{N} 235$ was acidified using $2 \mathrm{~mol} / \mathrm{l} \mathrm{HCl}$ (volume ratio $1: 1)$ before use ${ }^{14}$. The extraction was performed at ambient temperature with organic/aqueous $(\mathrm{O} / \mathrm{A})$ ratio of 1:6, and 3 min equilibrium time. Table 4 shows that the $\mathrm{pH}$ had a significant effect on extraction efficiency with an optimal $\mathrm{pH}$ of approximately 3.5. $\mathrm{NaOH}$ was used as stripping agent with stripping experimental conditions as $\mathrm{O} / \mathrm{A}$ ratio of $2: 1$, ambient temperature and equilibrium time of $4 \mathrm{~min}$. Table 5 shows the effect of $\mathrm{NaOH}$ concentration on stripping efficiency. The stripping efficiency increased with increase in

Table 4 Effect of $\mathrm{pH}$ on extraction efficiency.

\begin{tabular}{lccccc}
\hline Solution $\mathrm{pH}$ & 1.98 & 2.31 & 2.62 & 3.43 & 4.28 \\
\hline $\begin{array}{l}\text { Concentration of } \mathrm{V}_{2} \mathrm{O}_{5} \\
\text { in raffinate }(\mathrm{g} / \mathrm{l})\end{array}$ & 0.84 & 0.33 & 0.17 & 0.033 & 0.25 \\
Extraction efficiency $(\%)$ & 89.3 & 95.8 & 97.8 & 99.7 & 96.8 \\
\hline
\end{tabular}

Table 5 Effect of $\mathrm{NaOH}$ concentration on stripping efficiency.

\begin{tabular}{lcccc}
\hline Concentration of $\mathrm{NaOH}(\%)$ & 2 & 4 & 6 & 8 \\
\hline Concentration of $\mathrm{V}_{2} \mathrm{O}_{5}$ & 84.5 & 87.3 & 89.5 & 91.5 \\
in stripping liquor $(\mathrm{g} / \mathrm{l})$ & 90.7 & 93.7 & 96.0 & 98.2 \\
Stripping efficiency $(\%)$ & 9.7 &
\end{tabular}

Table 6 Effect of $\mathrm{pH}$ on precipitation efficiency of ammonium metavanadate.

\begin{tabular}{lcccc}
\hline $\mathrm{pH}$ & 6.1 & 7.3 & 8.2 & 9.5 \\
\hline $\begin{array}{l}\text { Concentration of } \mathrm{V}_{2} \mathrm{O}_{5} \\
\text { in residual liquor }(\mathrm{g} / \mathrm{l})\end{array}$ & 0.57 & 0.85 & 1.59 & 3.13 \\
$\begin{array}{l}\text { Precipitation efficiency } \\
\text { of vanadium (\%) }\end{array}$ & 99.4 & 99.1 & 98.2 & 96.7 \\
\hline
\end{tabular}

$\mathrm{NaOH}$ concentration. When the $\mathrm{NaOH}$ concentration was 6 and $8 \%$, the stripping efficiency reached 96.02 and $98.2 \%$, respectively. However, for the $\mathrm{NaOH}$ concentration of $8 \%$, a crystalline phase forms, which is harmful to the stripping process. Thus a suitable $\mathrm{NaOH}$ concentration is $6 \%$.

\section{Precipitation of ammonium metavanadate and $\mathrm{V}_{2} \mathrm{O}_{5}$}

After stripping, the vanadium was enriched, and the $\mathrm{V}_{2} \mathrm{O}_{5}$ concentration in the stripping liquor reached approximately $90 \mathrm{~g} / \mathrm{l}$. This concentration was sufficient for ammonium metavanadate precipitation ${ }^{15}$. As $\mathrm{NH}_{4} \mathrm{NO}_{3}$ was added to the stripping liquor at $35^{\circ} \mathrm{C}$, and ammonium metavanadate crystallized from solution. The $\mathrm{NH}_{4} \mathrm{NO}_{3}$ dosage was $80 \mathrm{~g} \mathrm{NH}_{4} \mathrm{NO}_{3}$ per stripping liquor. The effect of $\mathrm{pH}$ on the precipitation efficiency of vanadium was investigated with results shown in Table 6 . The vanadium precipitation efficiency decreases with increase in $\mathrm{pH}$. When the $\mathrm{pH}$ is 6-7, the vanadium precipitation efficiency reaches $99 \%$ and this $\mathrm{pH}$ range is therefore suitable.

$\mathrm{NH}_{4} \mathrm{VO}_{3}$ was roasted in a muffle furnace at $500{ }^{\circ} \mathrm{C}$ for $1 \mathrm{~h}$ to obtain $\mathrm{V}_{2} \mathrm{O}_{5}$. The $\mathrm{V}_{2} \mathrm{O}_{5}$ purity reached $99.6 \%$, meeting the standard specification. SEM images of the $\mathrm{V}_{2} \mathrm{O}_{5}$ formed are provided in Fig. 4.

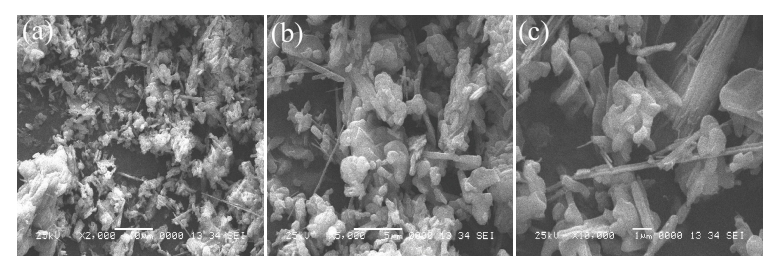

Fig. 4 SEM images of the vanadium pentoxide formed: (a) 2000 times magnification, (b) 5000 times magnification, and (c) 10000 times magnification. 


\section{CONCLUSIONS}

The recovery of vanadium from the alkaline leaching solution of roasted stone coal was performed by twostage purification, solvent extraction, stripping, precipitation of ammonium metavanadate and preparation of $\mathrm{V}_{2} \mathrm{O}_{5}$. The overall vanadium recovery was $90.9 \%$ with $\mathrm{V}_{2} \mathrm{O}_{5}$ purity of $99.6 \%$, thereby meeting the standard specification. This technology has advantages of higher recovery, production purity and environmental safety.

Acknowledgements: This work was supported financially by the National Natural Science Foundation of China (No. 50974133) and National Key Technology Research and Development Program of the Ministry of Science and Technology of China (Grant No. 2012BAB07B02).

\section{REFERENCES}

1. Moskalyk RR, Alfantazi AM (2003) Processing of vanadium: a review. Miner Eng 16, 793-805.

2. Cai JQ (2001) New technology of the production of vanadium from stone coal. Inorg Chemicals Ind 33, 37-8.

3. Zeng L, Li QG, Xiao LS, Zhang QX (2010) A study of the vanadium species in an acid leach solution of stone coal using ion exchange resin. Hydrometallurgy $\mathbf{1 0 5}$, 176-8.

4. Qi MJ (1999) The status and prospects of vanadium leaching from stone coal. Hydrometall China 18, 1-10.

5. Chen XY, Lan XZ, Zhang QL, Ma HZ, Zhou J (2010) Leaching vanadium by high concentration sulfuric acid from stone coal. Trans Nonferr Met Soc China 20, s123-6.

6. Zhang YM, Bao SX, Liu T, Chen TJ, Huang J (2011) The technology of extracting vanadium from stone coal in China: History, current status and future prospects. Hydrometallurgy 109, 116-24.

7. Li MT, Wei C, Li CX, Deng ZG, Li XB, Fan G (2010) Technics for vanadium pentoxide extraction from black shale in pressure field. J Cent S Univ 41, 1268-75.

8. Bin ZY (2006) Progress of the research on extraction of vanadium pentoxide from stone coal and the market of the $\mathrm{V}_{2} \mathrm{O}_{5}$. Hunan Nonferr Met 22, 16-20.

9. He DS, Feng QM, Zhang GF, Ou LM, Lu YP (2007) An environmentally-friendly technology of vanadium extraction from stone coal. Miner Eng 20, 1184-6.

10. He DS, Feng QM, Zhang GF, Ou LM, Lu YP, Shao YH (2007) The study on leaching vanadium from stone coal with alkali. Nonferr Met (Extr Metall) 2007-04, 15-7.

11. Battistoni P, Fava G, Pavan P, Musacco A, Cecchi F (1997) Phosphate removal in anaerobic liquors by struvite crystallization without addition of chemicals: Preliminary results. Water Res 31, 2925-9.

12. Stratful I, Scrimshaw MD, Lester JN (2001) Conditions influencing the precipitation of magnesium ammonium phosphate. Water Res 35, 4191-9.

13. Zeng L, Cheng CY (2009) A literature review of the recovery of molybdenum and vanadium from spent hydrodesulphurisation catalysts Part II: Separation and purification. Hydrometallurgy 98, 10-20.

14. Chen Y, Feng QM, Shao YH, Zhang GF, Ou LM, Lu YP (2006) Investigations on the extraction of molybdenum and vanadium from ammonia leaching residue of spent catalyst. Int J Miner Process 79, 42-8.

15. Luo L, Miyazaki T, Shibayama A, Yen W, Fujita T (2003) A novel process for recovery of tungsten and vanadium from a leach solution of tungsten alloy scrap. Miner Eng 16, 665-70. 